\title{
Standards for total body fat and fat-free mass in infants
}

Niels C de Bruin, Karin A M van Velthoven, Maria de Ridder, Theo Stijnen, Rikard E Juttmann, Herman J Degenhart, Henk K A Visser

\begin{abstract}
Data on body composition in conjunction with reference centiles are helpful in identifying the severity of growth and nutritional disorders in infancy and for evaluating the adequacy of treatment given during this important period of rapid growth. Total body fat (TBF) and fat-free mass (FFM) were estimated from total body electrical conductivity (TBEC) measurements in 423 healthy term Caucasian infants, aged 14-379 days. Cross sectional age, weight, and length related centile standards are presented for TBF and FFM. Centiles were calculated using Altman's method, based on polynomial regression and modelling of the residual variation. The TBF percentage steeply increased during the first half year of life, and slowly declined beyond this age. Various simple TBEC derived anthropometric prediction equations for TBF and FFM are available to be used in conjunction with these standards. Regression equations for the P50 and the residual SD, depending on age, weight, or length, are provided for constructing centile charts and calculating standard deviation scores.

(Arch Dis Child 1996; 74: 386-399)
\end{abstract}

Department of Paediatrics, Erasmus University and University Hospital Rotterdam/Sophia Children's Hospital, Rotterdam, The

Netherlands

N C de Bruin

K A M van Velthoven

H J Degenhart

H K A Visser

Department of Epidemiology and Biostatistics, Erasmus

University Rotterdam,

The Netherlands

$M$ de Ridder

T Stijnen

Rotterdam Home Care Foundation,

Department of Public

Health, Erasmus

University Rotterdam,

The Netherlands

R E Juttmann

Correspondence to:

Dr N C de Bruin,

Department of

Paediatrics/Sophia

Children's Hospital, Dr

Molewaterplein 60, $3015 \mathrm{GJ}$

Rotterdam, The

Netherlands.

Accepted 8 January 1996 centile standards on total body fat (TBF) and fat-free mass (FFM) in infants have not yet been published.

Limited data are available on the body composition of human infants and the changes that occur during the first year of life. The paucity of data is mainly due to the limitations of existing methods of measurement, which are either invasive, use radioactivity, or require cooperation of the subject. Traditionally, nutritional status in infants has been assessed using skinfold measurements, ${ }^{10} 11$ arm muscle area, or body mass index, 1213 which are relatively insensitive; however, their accuracy in predicting fat and lean mass has been found to be limited in infants. ${ }^{14}$ Skinfold measurements are notorious for their interobserver variation and the inaccuracy in untrained hands, ${ }^{14} 15$ which makes them less useful in most clinical settings, with different clinicians involved in the treatment of a child. Moreover, it has been shown that skinfold thickness in infants is poorly related to total body fatness. ${ }^{16} \mathrm{~A}$ rather accurate estimate of body water and hence FFM, and to a lesser extent TBF, can be obtained by the dilution technique using labelled water. ${ }^{17}$ However, this technique is too expensive and cumbersome for measuring the large numbers of infants needed for the calculation of accurate reference centiles.

Recently measurement of total body electrical conductivity (TBEC) has emerged as an accurate, precise, and reproducible method for the estimation of FFM and TBF in infants. ${ }^{18-20}$ TBEC measurement is rapid, safe, easy to perform, and suitable for measurement of large numbers of infants. The instrument has been commercially available since 1989 . At present TBEC is the most reliable convenient method for routine estimations of infant body composition, but is not widely used because of the (still) relatively high price of a TBEC instrument (approximately $\$ 45000$ ), and the fact that the instrument is large and difficult to move and therefore not suitable for field studies. However, its good reproducibility, precision, and accuracy justifies the use of TBEC as a reference method.

We present for the first time centile standards for TBF and FFM by gender for infants aged from 1 to 12 months. We recently published various simple, TBEC derived anthropometric prediction equations for TBF and FFM $^{14}$ which can be used in conjunction with the centile standards presented in this study. Because changes in body composition are associated with changes in length and weight, centiles for TBF and FFM were constructed against length and weight as well as against age. Regression equations for the P50 and the residual SD, depending on age, weight, or length, are provided for constructing charts and calculating standard deviation scores. 
Methods

In cooperation with the local child health clinics of the Rotterdam Home Care Foundation, a random sample of 2000 infants (living in the Rotterdam metropolitan area and aged between 1 and 12 months) was drawn from their database. These families were sent a letter with detailed information on the study, in which they were invited to participate in the study. A total of 601 parents responded. For reasons of anonymity, non-responding families could not be checked for socioeconomic status, birthweight, and so on. To ensure an optimal representation of the general population, no selection of the 601 infants was made on the basis of length, weight, or body fatness; selection was only made on the basis that the mother and infant were healthy. All infants with no history of chronic illness, born from healthy mothers with no history of major pathology during pregnancy or delivery and not under chronic medication, were enrolled in the study. After enrolment the parents were sent an invitation to attend for the measurement and a questionnaire to record parental weight, height, health, socioeconomic status, nationality, family constitution, and other details. Information on pregnancy, labour, the infant's birth weight, early growth, feeding, and state of health was also obtained. The data on all healthy Caucasian infants $(n=423)$ were selected for the present study. Written informed consent was obtained from the parents. The study protocol was approved by the ethics review boards of the Erasmus University/University Hospital Rotterdam and the Rotterdam Home Care Foundation.

\section{BEC MEASUREMENTS}

Details about the TBEC method, accuracy, reproducibility, the calibration equation used, and the calculation of TBF and FFM have been published before. ${ }^{18-23}$ Briefly, the TBEC instrument (model HP-2; EM-Scan Inc, Springfield, Illinois, USA) is a large solenoidal coil driven by a $2.5 \mathrm{MHz}$ oscillating radiofrequency current. The principle underlying TBEC is that lean tissue is far more electrically conductive than fat, due to the much greater content of electrolytes dispersed in the FFM. When a conductive mass passes through the electromagnetic field, the magnetic component of the field induces small eddy currents within the conductive mass, producing a small amount of heat. The energy of the eddy currents is dissipated from the magnetic field. The total energy loss is detected as a phase change in coil impedance. This phase change serves as an index of the amount of conductive mass. The amount of fat is calculated by subtraction of the estimated conductive mass (the FFM) from body weight. Electric and magnetic field intensities are less than $0.02 \%$ and $0.4 \%$ respectively of the American National Standards Institute limits $\left(\mathrm{mW} / \mathrm{cm}^{2}\right)$ for continuous human exposure. ${ }^{21}$

Body temperature affects TBEC outcome ${ }^{22}$; therefore infants with apparent fever or illness were measured after recovery. Infants were not fed for at least two hours before the measurement. To prevent cooling and to ensure geometric homogeneity between infants with respect to the introduction of the conductive mass into the electromagnetic field, infants were undressed and carefully swaddled in a large blanket, while care was taken that limbs were not flexed and did not touch each other or the trunk. Infants were placed on their back on the sledge of the instrument. A pacifier was allowed when necessary. One TBEC reading took approximately 10 seconds. A complete TBEC measurement consisted of 10 reliable 10 -s readings which were averaged for the FFM calculation. If urination occurred, the infant was swaddled again in a dry blanket and remeasured. Movement or crying during a reading was also a reason for remeasuring the infant. In the present study background measurements averaged 39.6 (SD 2.9) TBEC units and the coefficient of variation (CV) of the ten 10 -s TBEC readings was $1 \cdot 24(0.58) \%$.

After the TBEC measurement infants were weighed naked on an electronic baby scale (Instru Vaaka Oy, Vaany, Finland) to the nearest $1 \mathrm{~g}(0-3 \mathrm{~kg}), 2 \mathrm{~g}(3-6 \mathrm{~kg})$, or $5 \mathrm{~g}(6-10 \mathrm{~kg})$, and recumbent crown-heel length was measured to the next succeeding $\mathrm{mm}$ on a length board. Fronto-occipital head circumference was measured to the nearest $\mathrm{mm}$ with a 1 $\mathrm{cm}$ wide standard plastic measurement tape.

\section{STATISTICAL PROCEDURE}

Centiles were constructed from the raw data using Altman's procedure. ${ }^{24}$ A detailed description is given in the appendix. TBF $(\mathrm{kg})$, TBF (\%), and FFM (kg) were used as dependent $(\mathrm{Y})$ variables. Age (months), weight $(\mathrm{kg})$, and length $(\mathrm{cm})$ were used as independent $(\mathrm{X})$ variables. All calculations were performed separately for boys and girls. The validity of the centiles was assessed by calculating the percentage of data points above and below the 10 th and 90 th centile and tested for significant deviation from the expected distribution by the $\chi^{2}$ test. ${ }^{26}$ Details on the assessment of the accuracy and precision of the centiles are described in the appendix. An effect was assumed to be statistically significant at a value of $<0 \cdot 05$.

\section{Results}

Subject characteristics are summarised in table 1. A significant difference between sexes was present for weight, length, TBF percentage, FFM, and head circumference. The distribution of body lengths and weights was in agreement with the Dutch growth chart centiles. ${ }^{25}$ All infants were born at term without a history of serious illness, and were clinically healthy at the time of the measurement. Mean gestational age of the infants was $40.0(1.3)$ weeks, range 37.0 to 43.3 . Table 2 shows the most important environmental factors that might affect infant growth and body composition.

\section{REFERENCE CENTILES}

Figures 1 to 9 show the original data points for 
Table 1 Characteristics of the study group

\begin{tabular}{|c|c|c|c|c|c|}
\hline & \multicolumn{2}{|l|}{ Boys $(n=221)$} & \multicolumn{2}{|l|}{ Girls $(n=202)$} & \\
\hline & Mean & Range & Mean & Range & \\
\hline \multicolumn{6}{|l|}{ Infants } \\
\hline Age (months) & $5 \cdot 79$ & $0 \cdot 8-12 \cdot 3$ & $6 \cdot 2$ & $4 \cdot 7-12 \cdot 6$ & $\mathrm{NS}^{1}$ \\
\hline Weight $(\mathrm{kg})$ & $7 \cdot 56$ & $3 \cdot 77-11 \cdot 9$ & $7 \cdot 20$ & $3 \cdot 41-10 \cdot 8$ & $\mathrm{p}<0.001$ \\
\hline Length $(\mathrm{cm})$ & $67 \cdot 7$ & $54 \cdot 0-83 \cdot 0$ & $67 \cdot 1$ & $51-82 \cdot 4$ & $\mathrm{p}<0.001$ \\
\hline TBF $(\mathrm{kg})$ & 1.85 & $0 \cdot 16-4 \cdot 06$ & $1 \cdot 85$ & $0.37-3.59$ & NS \\
\hline TBF (\%) & $23 \cdot 4$ & $3 \cdot 79-36 \cdot 5$ & $24 \cdot 7$ & $9 \cdot 84-36 \cdot 7$ & $p=0.005$ \\
\hline FFM (kg) & $5 \cdot 71$ & $3 \cdot 30-8 \cdot 88$ & $5 \cdot 34$ & $3 \cdot 01-8.00$ & $\mathrm{p}<0.001$ \\
\hline \multicolumn{6}{|l|}{ Head circumference } \\
\hline \multicolumn{6}{|l|}{ Parents } \\
\hline Length mother $(\mathrm{cm})$ & $169(6)^{2}$ & $152-185$ & $169(6)^{2}$ & $156-189$ & NS \\
\hline Length father $(\mathrm{cm})$ & $182(7)$ & $161-203$ & $183(7)$ & $165-204$ & NS \\
\hline Weight mother $(\mathrm{kg})$ & $66.4(11 \cdot 0)$ & $44-110$ & $66.4(11 \cdot 5)$ & $46-120$ & NS \\
\hline Weight father $(\mathrm{kg})$ & $80 \cdot 8(10 \cdot 5)$ & $59-117$ & $79 \cdot 9(12 \cdot 1)$ & $56-135$ & NS \\
\hline
\end{tabular}

$\mathrm{TBF}=$ total body fat; $\mathrm{FFM}=$ fat-free mass.

${ }^{1}$ Differences between boys and girls were tested for infant parameters by ANOVA with age and $\mathrm{age}^{2}$ as covariable, and for parental parameters by Student $t$ test (NS=not significant).

2 Mean (SD). in infants are scarce and only average values derived from carcass analysis ${ }^{27} 28$ or calculated from indirect body composition estimates ${ }^{29}$ have been published so far. The distribution of biological scatter in TBF and FFM has not yet been quantified for growing infants. This is due to the fact that, until recently, no body composition method was accurate, simple, and convenient enough to measure the number of infants needed for calculation of accurate reference centiles.

In figs 1 to 9 , the widely known body composition reference values published by Fomon et $a l^{29}$ have been plotted in the centile charts. Fomon's age and weight related reference curves lie within our 25th and 75th centile range. From the position of Fomon's length related curves in our centile standards, it can be seen that Fomon's infants were on average smaller in length, possessed equal amounts of fat, but had relatively more FFM per unit length compared with our study population. Most probably this can be attributed to a secular trend in length growth in the past 25 years, and to infant diet: whereas Fomon's infants were bottle fed (old fashioned formula), over half of the infants from the present study were breast fed.

Fomon's reference values for TBF (kg and per cent) fall from above P50 to below P50. An artefact caused by TBEC is not likely since De Bruin et al showed that FFM and TBF measurements obtained from TBEC and isotope dilution are strictly linearly related and not significantly different throughout the entire first year of life. ${ }^{20}$ The difference might be accounted for by several factors. (1) Fomon used weight, length, and total body water data for his 0-4 month population from formula fed infants, and he used 1979 NCHS data for his 3-10 year population; he then interpolated the TBF values proportionally to truncal skinfold thicknesses for 4 months to 3 years of age. (2) Feeding habits have changed over time; the feeding pattern of our study population are a better reflection of modern feeding habits (with a high proportion of breast feeding). Our body composition data are thus likely to be a better reflection of the average body composition of present day infants. (3) Fomon used longitudinal data, while in the our study cross sectional data were used. However, the differences are so great it is unlikely they could be attributed to this.

\section{NUTRITIONAL ASSESSMENT}

Body composition data give a better insight in nutritional status and quality of growth than body weight alone, or than achieved by routine clinical examination. ${ }^{30}$ Cross et al compared routine clinical examination by a paediatrician with upper arm circumference as the standard measure of nutritional status in infants. ${ }^{30} \mathrm{We}$ recently showed, however, that upper arm circumference in infants is very poorly correlated with TBF and FFM. ${ }^{14}$ Skinfold measurements and Quetelet's index have also been found to be poorly correlated with TBF. ${ }^{14161831}$ So we can conclude that in infants these local
${ }^{1}$ No significant differences were found in total body fat, per cent total body fat, and fat-free mass between education profession, or parity subgroups (by one way analysis of variance).

${ }^{2}$ Percentage of fathers/percentage of mothers. 


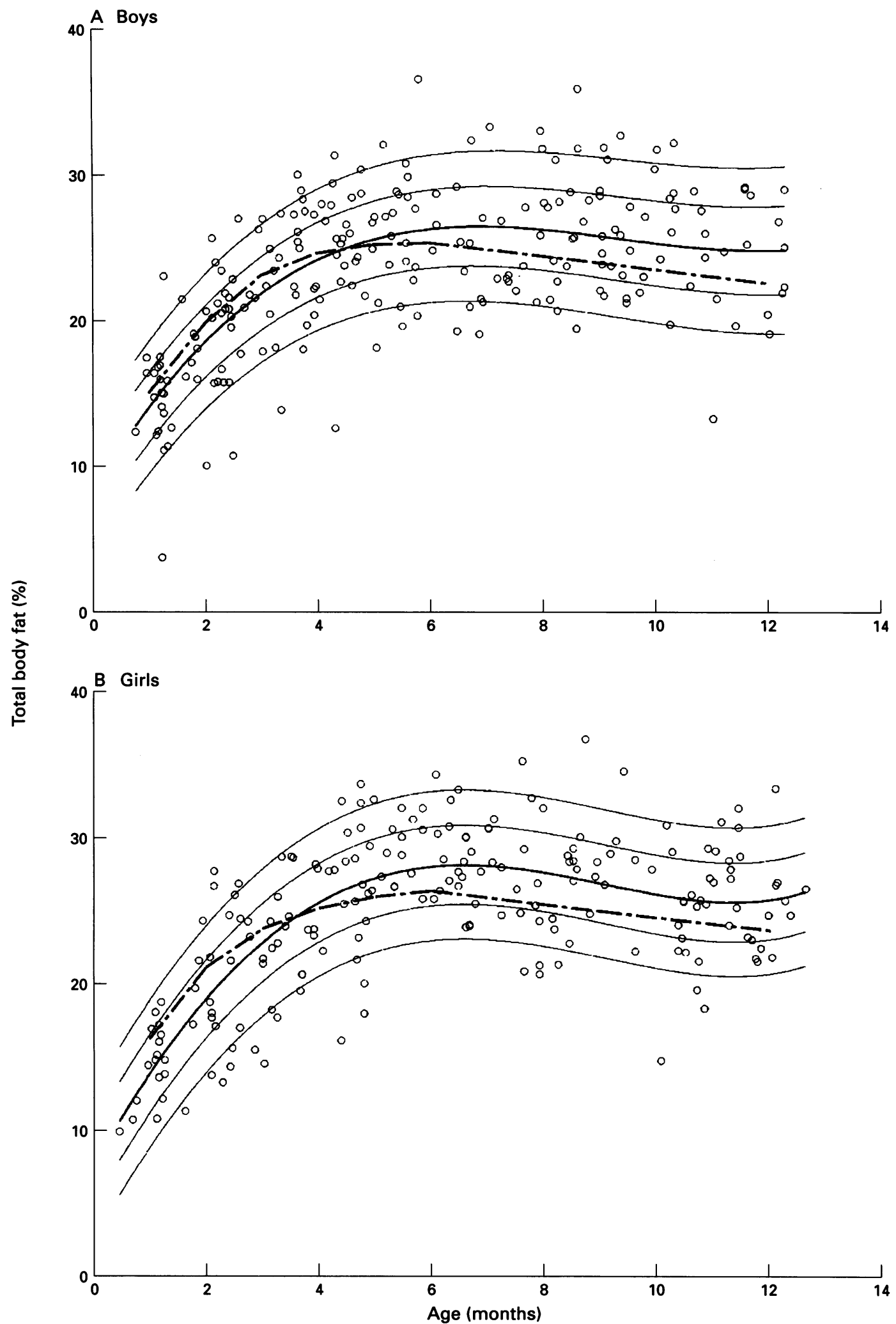

Figure 1 Individual data points and 10th, 25th, 50th, 75th, and 90th centiles of per cent total body fat [TBF (\%)] plotted against age for boys and girls. Dotted line represents the reference data from Fomon et al. ${ }^{19}$

anthropometric measurements, used in children and adults as a proxy for total body composition, are a poor reflection of the actual total energy and protein stores of the infant's body. Centile charts of these variables ${ }^{10-12}$ are therefore of limited value in infants. Measurement of total body composition, represented by TBF and FFM, will provide better estimates of nutritional reserves than regional anthropometric measurements and may provide a more accurate assessment of nutritional status. For infants, quantitation of TBF has been performed traditionally using the anthropometric method of Dauncey et al. ${ }^{32}$ This method has only very recently been validated for the first time and was shown to have moderate accuracy but poor precision. ${ }^{18} 33$ However, this does not inevitably mean that anthropometric measurements are obsolete. We recently published - specifically for use in infants - new 


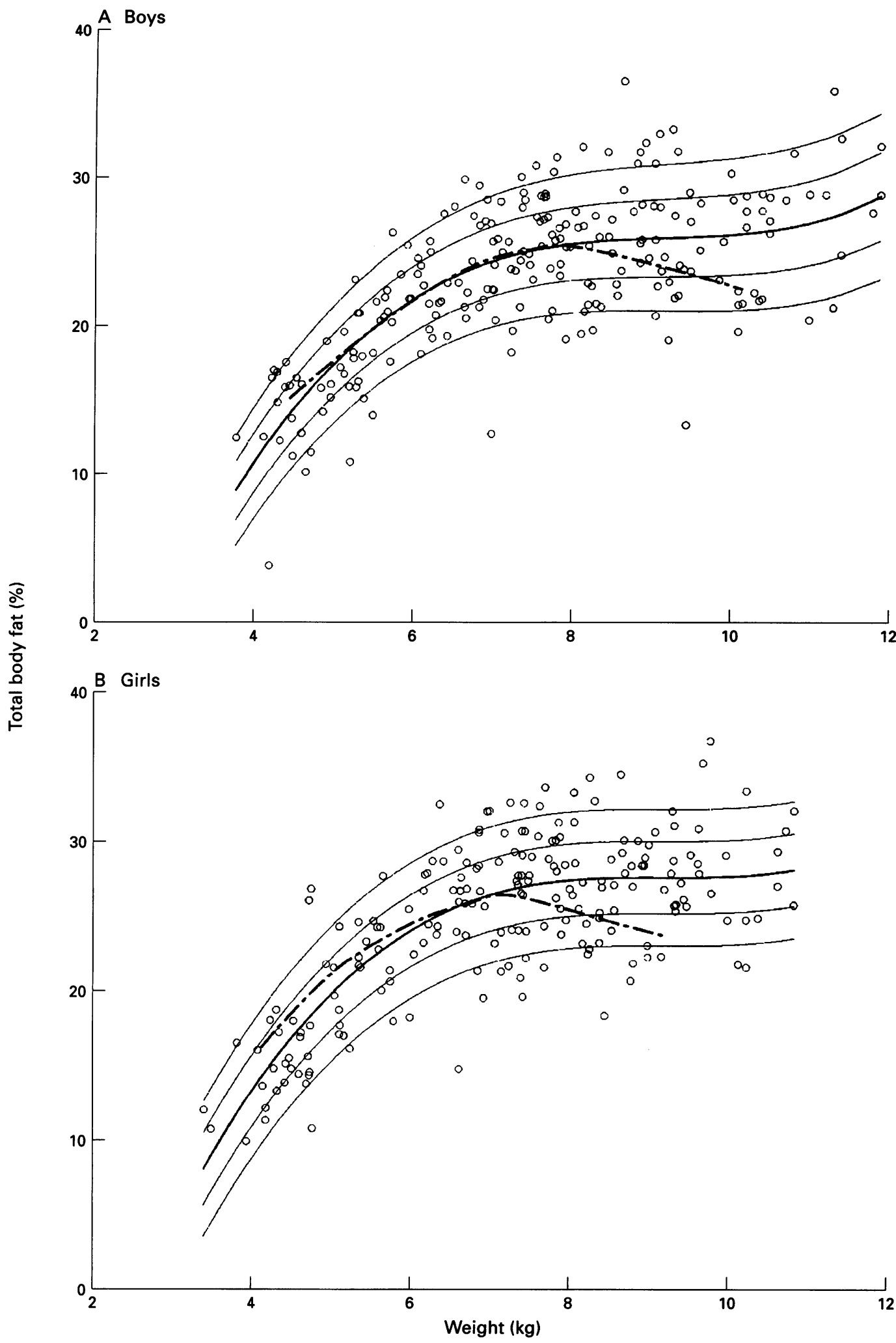

Figure 2 Individual data points and 10th, 25th, 50th, 75th, and 90th centiles of per cent total body fat [TBF (\%)] plotted against weight for boys and girls. Dotted line represents the reference data from Fomon et al. ${ }^{19}$

TBF and FFM prediction equations based on a variety of anthropometric measurements, which correlate much better with TBF and FFM. ${ }^{14}$ Depending upon the available anthropometric data the appropriate equations can be chosen. We here give as an example:

$\mathrm{TBF}=\exp (-0.358+1.499[\mathrm{n}($ weight $\times$ calf circumference/length)])

$(\mathrm{SD}=0.25, r=0.93)$.
$\mathrm{TBF}=\exp (-6 \cdot 1506+1 \cdot 1453[1 \mathrm{n}$ (calf circumference) $]+0.8722[1 \mathrm{n}$ (weight) $]+0.4961$ [ 1 ( (sum of 3 skinfolds)]) $(\mathrm{SD}=0 \cdot 23, r=0.95)$.

FFM $=\exp (0.433+0.056[\mathrm{~V}($ weight $\times$ length $)])$ $(\mathrm{SD}=0.28, r=0.97)$.

where TBF, FFM, and weight are in $\mathbf{k g}$, length and calf circumference in $\mathrm{cm}$, and sum of three skinfolds (triceps, subscapular, and 

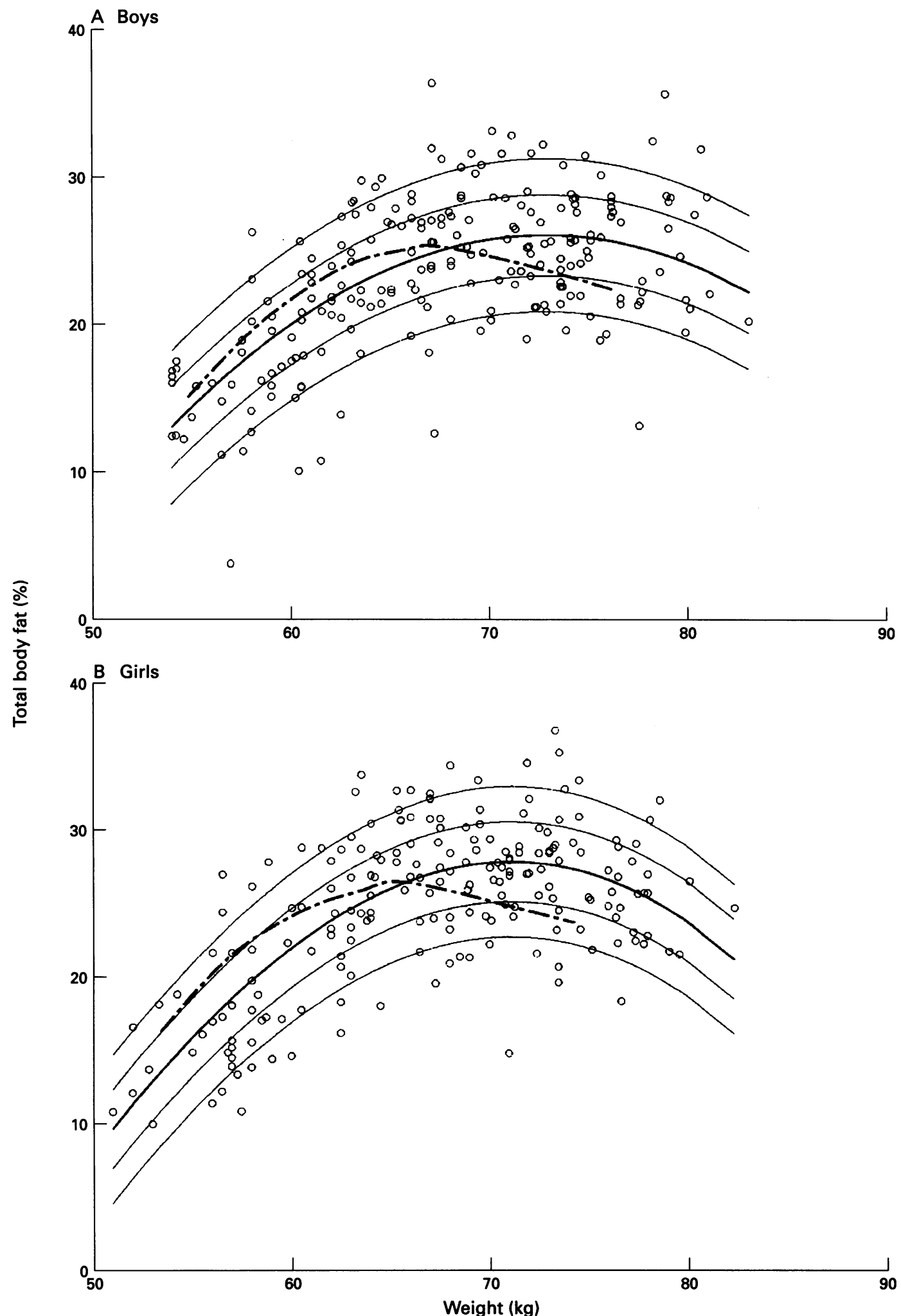

Figure 3 Individual data points and 10th, 25th, 50th, 75th, and 90th centiles of per cent total body fat [TBF (\%)] plotted against length for boys and girls. Dotted line represents the reference data from Fomon et al. ${ }^{19}$

quadriceps skinfold thickness) in $\mathrm{mm}$. When no accurate body composition method (for example, TBEC or isotope dilution) is available, these new anthropometry based prediction equations are a more accurate alternative for assessing nutritional status in infants than upper arm anthropometry or skinfold thickness, and we suggest they be used for screening purposes in conjunction with the present centile standards. However, anthropometric methods are still less precise than TBEC or isotope dilution; therefore one should remain cautious when using these data to derive individual total body composition estimations.

CHOICE OF REFERENCE METHOD

TBEC was chosen as the reference method of choice because at present it is the only accurate method that can easily supply large amounts of 


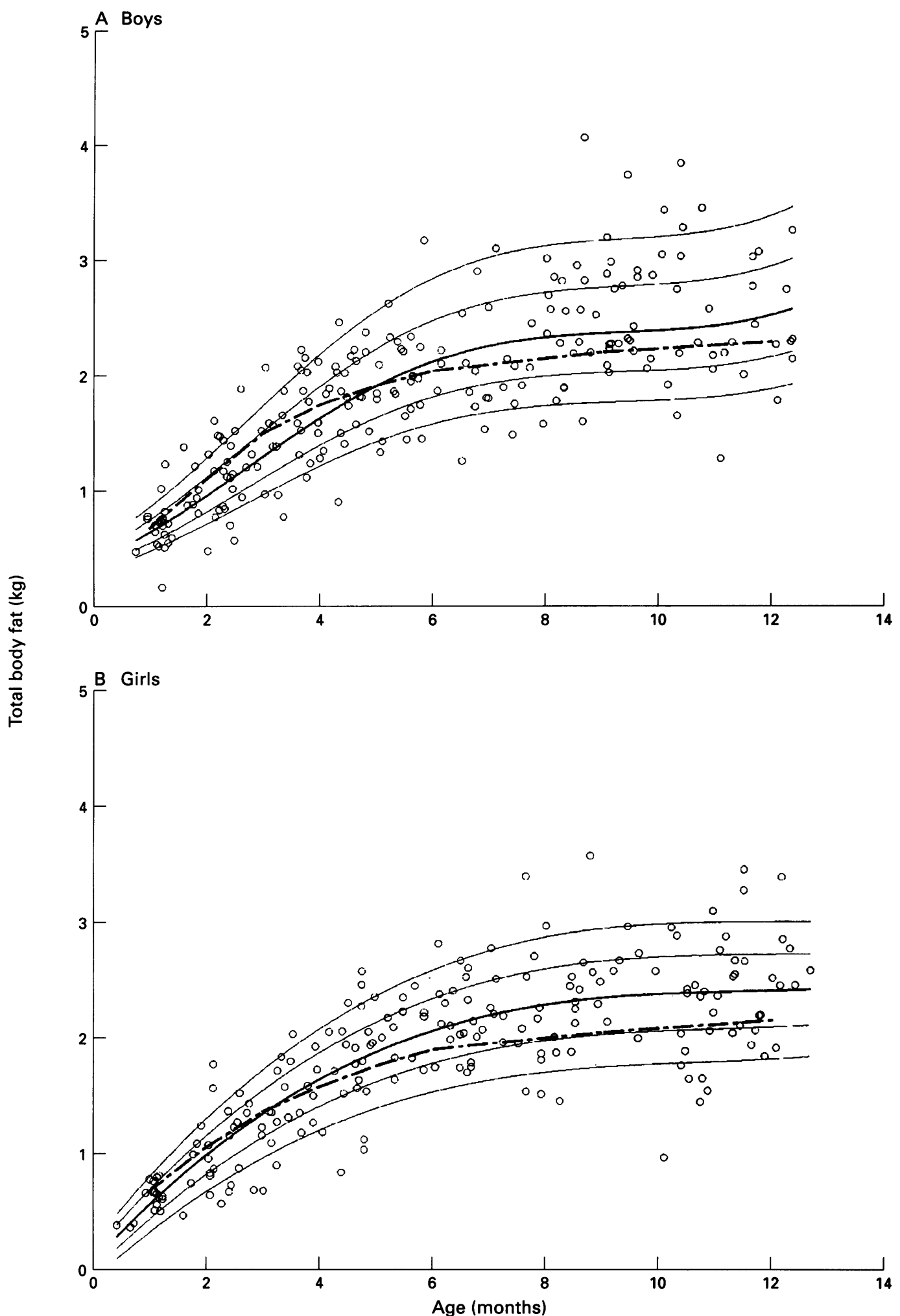

Figure 4 Individual data points and 10th, 25th, 50th, 75th, and 90th centiles of total body fat [TBF (kg)] plotted against age for boys and girls. Dotted line represents the reference data from Fomon et al. ${ }^{19}$

data on TBF and FFM in infants on a noninvasive basis. ${ }^{20}$ The method is already widely used in human adults and in animal research. The paediatric TBEC instrument, which has a much better coil copper winding construction and homogeneous electromagnetic field properties than the smaller TBEC coils for animal use, is rather robust concerning changes in hydration of the FFM compartment, ${ }^{34}$ so physiological changes in FFM hydration (that is, water content of the FFM) at a given age will not seriously affect TBEC outcome. ${ }^{22}$ Growth related physiological changes in hydration of the FFM, which occur during the process of FFM maturation and are most evident in early life, are accounted for by the calibration procedure. ${ }^{35}$ The paediatric TBEC instrument has been calibrated against carcass analysis data from minipigs, ${ }^{23}$ which showed that $99 \cdot 7 \%$ of the variability in TBEC outcome could be explained by the animals' FFM. The calibration equation showed an SD of $77 \mathrm{~g}$ 


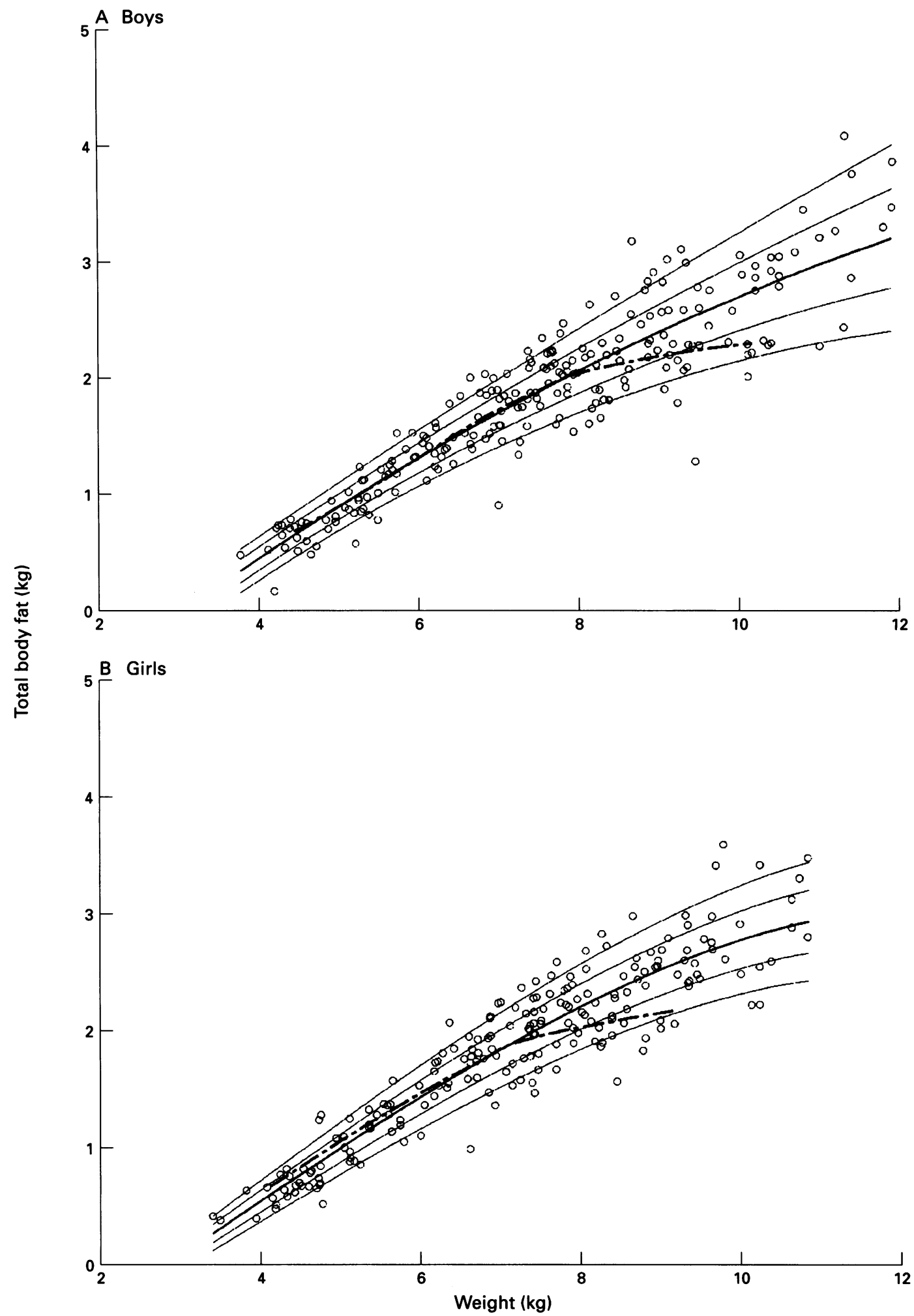

Figure 5 Individual data points and 10th, 25th, 50th, 75th, and 90th centiles of total body fat [TBF (kg)] plotted against weight for boys and girls. Dotted line represents the reference data from Fomon et al. ${ }^{19}$

which is consistent with an error of $\pm 154 \mathrm{~g}$ ( $95 \%$ confidence limits). The reasons for assuming that the minipig calibration equation can be extrapolated to human infants have been outlined in detail before. 192023 The accuracy of TBEC has been demonstrated in two ways. No significant difference was found between body composition values derived from labelled water and derived by TBEC in healthy term infants during the first year of life. ${ }^{20}$ Also, a 'seamless' join was found between the curves of TBF and FFM during intrauterine growth (measured by fetal carcass analysis, the gold standard) and during extrauterine growth (measured by TBEC). ${ }^{19}$ At present, therefore, TBEC is the body composition method of choice for nutritional assessment in conjunction with the present centile standards. It is to be expected that the price of the instrument will decrease in the near future, when the method will be more widely used in infants. 

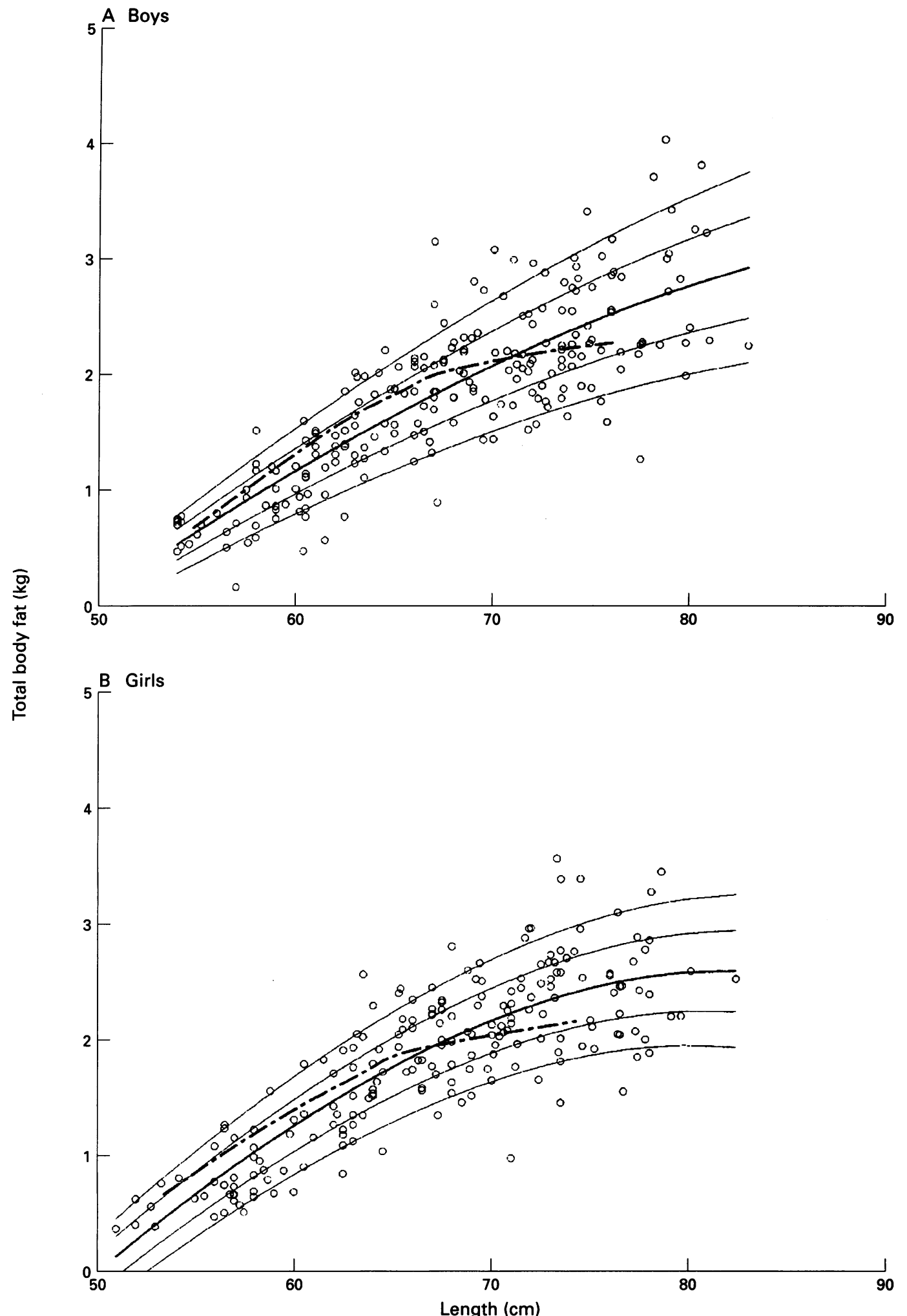

Figure 6 Individual data points and 10th, 25th, 50th, 75th, and 90th centiles of total body fat [TBF (kg)] plotted against length for boys and girls. Dotted line represents the reference data from Fomon et al. ${ }^{19}$

RELIABILITY AND ACCURACY OF THE CENTILES Our centiles were derived from Caucasian babies and do not necessarily apply to nonCaucasian infants. Although a limited number of infants was available, we took care that the sample was as representative as possible for the general population: only the infant's and mother's health were used as exclusion criteria. Healthy thin or obese babies, without a history of failure to thrive or chronic illness, were enrolled in the study.
It was not possible to account fully for parental socioeconomic status in this study. Firstly, it was not possible to check the socioeconomic status of the parents who did not respond, for reasons of anonymity of the randomly selected addresses. Secondly, in this study it was not possible to match each age group (for example, each month) for socioeconomic status: the total number of infants would become too limited for calculation of centiles. We therefore decided to include all 

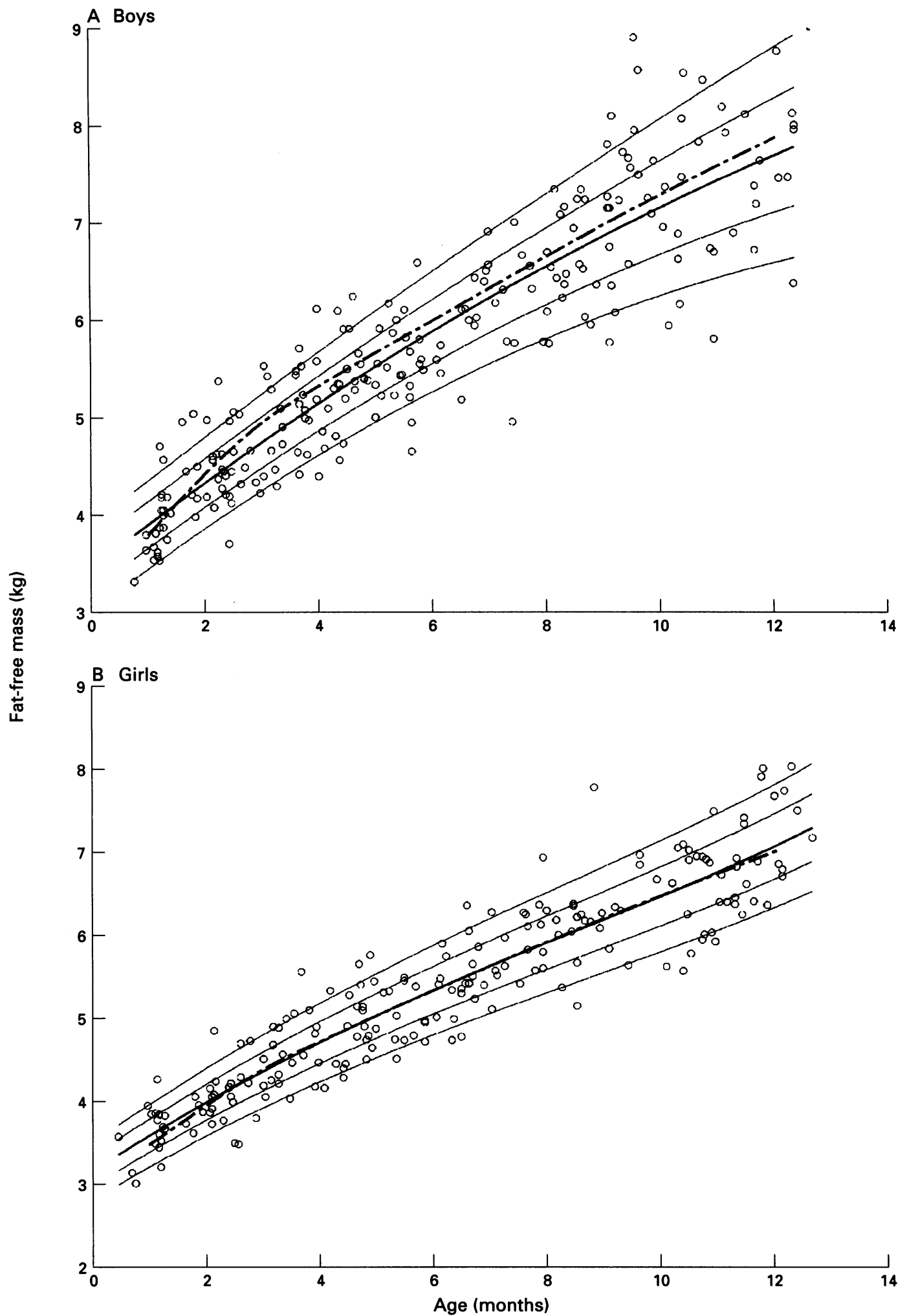

Figure 7 Individual data points and 10th, 25th, 50th, 75th, and 90th centiles of fat-free mass [FFM (kg)] plotted against age for boys and girls. Dotted line represents the reference data from Fomon et al. ${ }^{19}$

healthy infants meeting the inclusion criteria. Theoretically, bias resulting from a smaller number of infants from lower socioeconomic classes might result in a slight upward shift of the centiles. However, inclusion of more infants from lower socioeconomic classes would not have lowered the P10 centile in the present study, for, although effects of socioeconomic status on maternal smoking habits and birth weight have been described, socioeconomic status was not a significant risk factor for malnutrition or obesity in this cross sectional survey. We therefore conclude that socioeconomic effects on body composition in the first year of life are of limited importance, at least in the present study.

Because data on about 200 infants were available for the calculation of each centile chart, the present standards should be considered as the first quantitative description of the pattern of TBF and FFM growth in infants. An indication, therefore, of the accuracy of the 


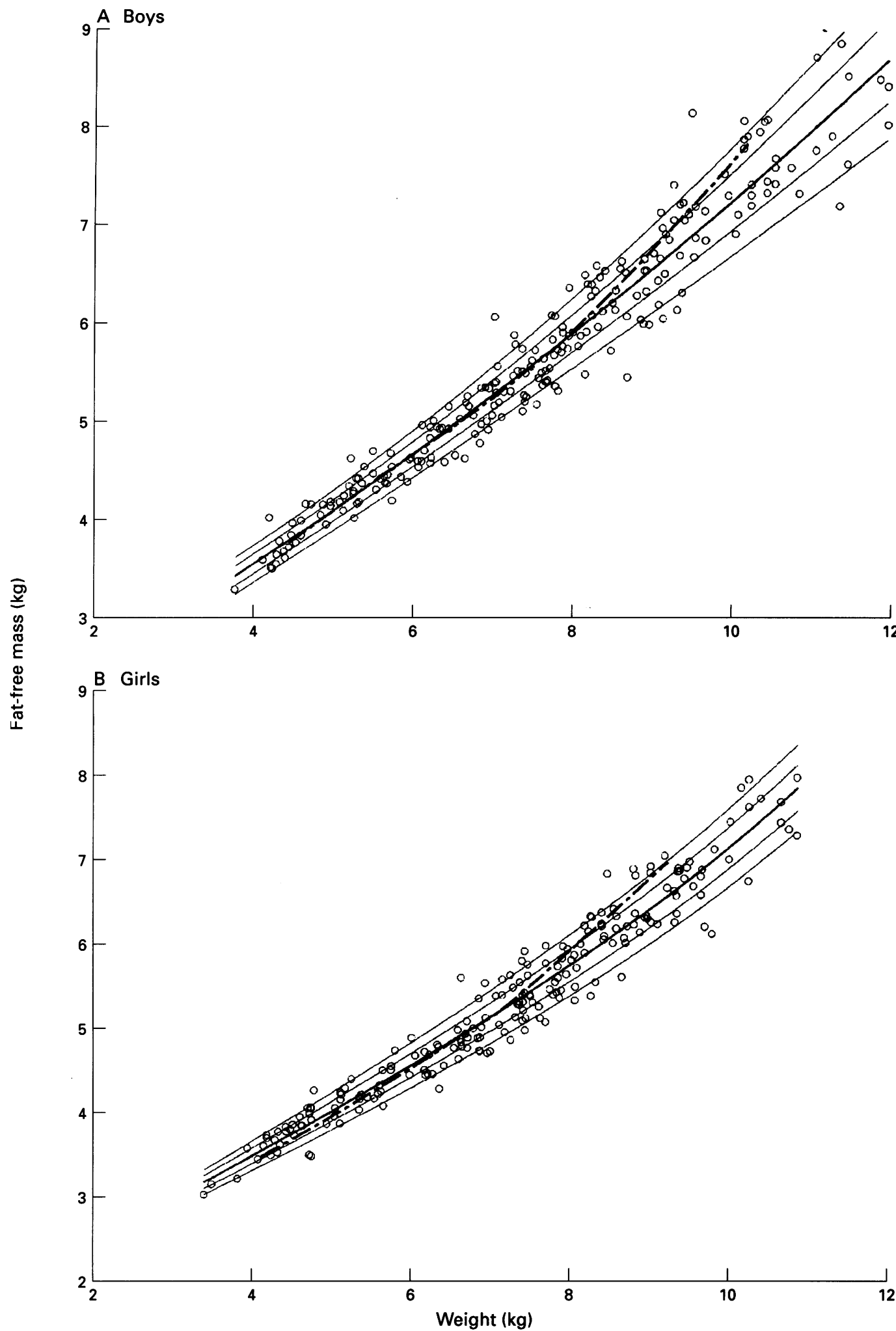

Figure 8 Individual data points and 10th, 25th, 50th, 75th, and 90th centiles of fat-free mass [FFM (kg)] plotted against weight for boys and girls. Dotted line represents the reference data from Fomon et al. ${ }^{19}$

centiles has been given in the appendix. Most centile standards are not accompanied by an assessment of the errors. However, when centile standards are based on limited numbers of data points, as often occurs, the error in the estimations, especially of those centiles or standard deviation scores that lie further away from the mean, can become significant. In the appendix we describe how the accuracy of the estimated centile curves can be assessed. To give an impression of the precision of the centile curves, we provided in fig A1 the P90, $\mathrm{P} 50$, and $\mathrm{P} 10$ of $\mathrm{TBF}(\%)$ versus age in girls, together with $90 \%$ confidence intervals. This shows that precision falls at both ends of the curves. It is necessary to consider these uncertainties when using the centile charts for comparison of individual body composition data.

CONCLUSION

We suggest that these centiles are a valid way 


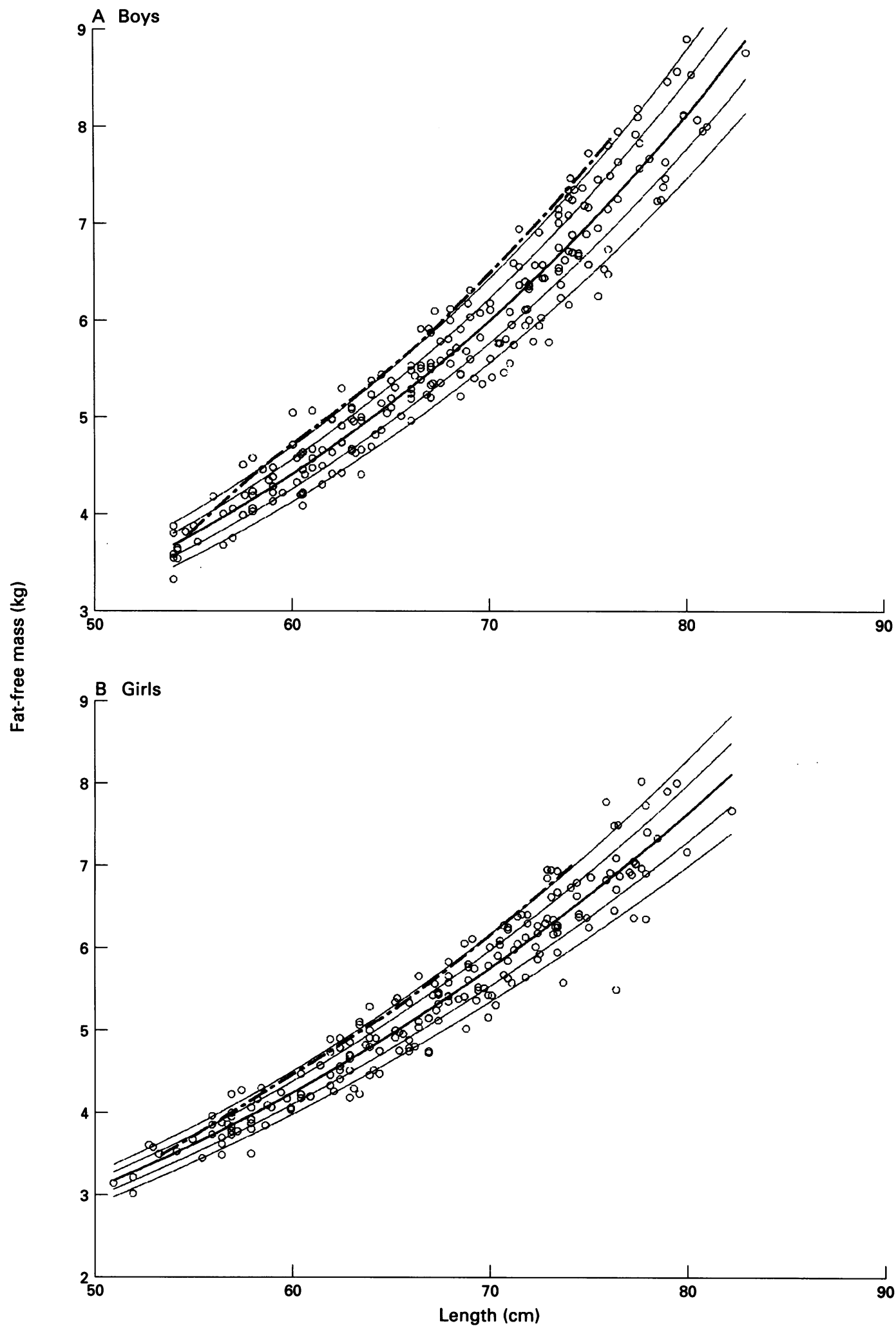

Figure 9 Individual data points and 10th, 25th, 50th, 75th, and 90th centiles of fat-free mass [FFM (kg)] plotted against length for boys and girls. Dotted line represents the reference data from Fomon et al. ${ }^{19}$

of monitoring nutritional status and the effect of treatment interventions in infants. Children at either extreme of the centile curves may be at risk of obesity or undernutrition, although at present the numbers of infants were insufficient for accurate prediction of more explicit extremes, for example the 97th and 3rd centiles. Further research should disclose the relation between infants at either extreme of the centile curves and the associated risk for future health hazards. The suggested relation between malnutrition in early life and adult chronic disease $\mathrm{e}^{2-5}$ and between obesity in infancy, childhood and adulthood ${ }^{79}$ certainly adds to this challenge.

We thank Dr T Cole (MRC Dunn Nutrition Unit, Cambridge, UK) for his helpful suggestions concerning centile construction with limited data. We gratefully acknowledge financial support from Praeventiefonds, Sophia Foundation for Medical Research, the University Hospital Rotterdam and Nutricia Research Laboratories. Gifts for the infants were provided by Procter \& Gamble Inc, Division Holland. 
Table 3 Percentage of all data points beyond the 10th and 90th percentile for each centile chart by gender

\begin{tabular}{|c|c|c|c|c|c|c|}
\hline \multirow[b]{2}{*}{$X$ variable } & \multicolumn{2}{|c|}{$T B F(\mathrm{~kg})$} & \multicolumn{2}{|c|}{$T B F(\%)$} & \multicolumn{2}{|c|}{$F F M(\mathrm{~kg})$} \\
\hline & $>P 90$ & $<P 10$ & $>P 90$ & $<P 10$ & $>P 90$ & $<P 1$ \\
\hline \multicolumn{7}{|l|}{ Boys } \\
\hline $\begin{array}{l}\text { Age } \\
\text { Length }\end{array}$ & $\begin{array}{r}7 \cdot 7 \\
8 \cdot 1 \\
10.0\end{array}$ & $\begin{array}{l}8 \cdot 6 \\
7 \cdot 7 \\
8 \cdot 6\end{array}$ & $\begin{array}{r}8.6 \\
9.5\end{array}$ & $\begin{array}{l}8 \cdot 6 \\
7 \cdot 7 \\
8 \cdot 6\end{array}$ & $\begin{array}{l}10 \cdot 9 \\
10 \cdot 4\end{array}$ & $\begin{array}{r}9 \cdot 5 \\
9 \cdot 5\end{array}$ \\
\hline Weight & $10 \cdot 0$ & $8 \cdot 6$ & $10 \cdot 9$ & $8 \cdot 6$ & $8 \cdot 6$ & $10 \cdot 0$ \\
\hline \multicolumn{7}{|l|}{ Girls } \\
\hline Age & $7 \cdot 4$ & $10 \cdot 4$ & $9 \cdot 9$ & $10 \cdot 4$ & $9 \cdot 4$ & 9.9 \\
\hline Length & 11.9 & $6 \cdot 9$ & 11.9 & $10 \cdot 4$ & 11.9 & 8.9 \\
\hline Weight & $10 \cdot 9$ & $10 \cdot 9$ & $9 \cdot 4$ & $10 \cdot 9$ & 10.9 & 10.9 \\
\hline
\end{tabular}

None of the distributions was significantly different from the expected (by the $\chi^{2}$ test).

$\mathrm{TBF}=$ total body fat; FFM $=$ fat-free mass; P90, P10 =90th centile, 10th centile.

\section{Appendix}

STATISTICAL PROCEDURE

Altman's approach based on modelling of absolute residuals was used for centile construction. ${ }^{24}$ Data analysis was performed with the SPSS for Windows ${ }^{\mathrm{TM}}$ (version 6.0) statistical package. Each P50 was fitted as a polynomial by entering first through fourth powers of the $\mathrm{X}$ variable into stepwise linear regression. Stepping method criteria for entry and removal were $p<0.05$ and $p>0.10$, respectively, and the tolerance criterion (used to prevent against collinearity) was set at 0.00001 . Residuals were examined for normality by the Lilliefors variant of the Kolmogorov-Smirnov test. In case of non-normality, $\mathrm{Y}$ was logarithmically transformed and the stepwise regression procedure was repeated with the transformed variable. At this stage, each residual plot was inspected visually for the presence of trends, and tested for positive autocorrelation by Durbin-Watson test ${ }^{36}$ and for negative autocorrelation by visual inspection of the plot of the residuals against their lagged ones. ${ }^{36}$ To allow dependence of the residual SD on X, the absolute values of the residuals were regressed on $\mathrm{X}$, as suggested by Altman. ${ }^{24}$ When a significant linear or quadratic relation was found, this relation was used to express the residual $\mathrm{SD}$ as a function of $\mathrm{X}$ and the stepwise regression procedure for the $\mathrm{P} 50$ was repeated once, now with $1 / \mathrm{SD}^{2}$ as the weighting factor.
In case no significant relation of the absolute residuals with $\mathrm{X}$ was found, the residual $\mathrm{SD}$ resulting from the stepwise polynomial regression was taken to calculate the centile standards as described below. In case of a significant relation of the absolute residuals with $\mathrm{X}$, the residual SD as dependent on $\mathrm{X}$ was estimated as the predicted mean resulting from the regression of the absolute residuals on $\mathrm{X}$, multiplied by $V(\pi / 2)$ (this factor is due to the fact that the absolute residuals follow approximately a half normal distribution, which has a mean of $V(\pi / 2)$ times the residual $S D)$. Subsequently centiles were calculated as $P 50 \pm k(S D)$, where $k$ is chosen as 1.282 and $0<0.674$ to give $90 \%$ and $75 \%$ reference intervals, and as -1.282 and -0.674 to give 10 and 25 per cent reference intervals.

\section{STATISTICAL RESULTS}

All data groups, except for one, showed a Lilliefors/Kolmogorov-Smirnov (K-S) test statistic with $\mathrm{p}>0 \cdot 2$, which is in agreement with a normal distribution. TBF $(\mathrm{kg})$ versus age in males was the only variable that needed a log transformation (K-S test statistic with $p=0.02$ ). In all but one regressions of TBF $(\mathrm{kg})$ and FFM $(\mathrm{kg})$ the residuals of $Y$ increased with the $\mathrm{X}$ variable (age, weight, or length). In these cases weighted stepwise linear regression was performed, with $1 / \mathrm{SD}^{2}$ as weighting factor. On careful visual inspection, the difference between weighted and unweighted curves was only apparent at the edges of the P50 (that is, disappearance after weighted regression of the typical 'dangling' curve ends artefacts often seen in higher degree polynomial regression).

\section{Regression coefficients}

Table A1 shows the regression coefficients of the P50 polynomials. For TBF (kg) against age in boys, the only dependent variable which was not approximately normally distributed and needed a log transformation, the regression is given in the form of $\ln (\mathrm{Y})=\mathrm{a}+\mathrm{bX}+\mathrm{cX} \mathrm{X}^{2}+\mathrm{dX}^{3}$. When the residual SD of the regression needed

Table A1 Regression coefficient of the 50th centile polynomials ${ }^{1}$ and of the regression their residual SDs

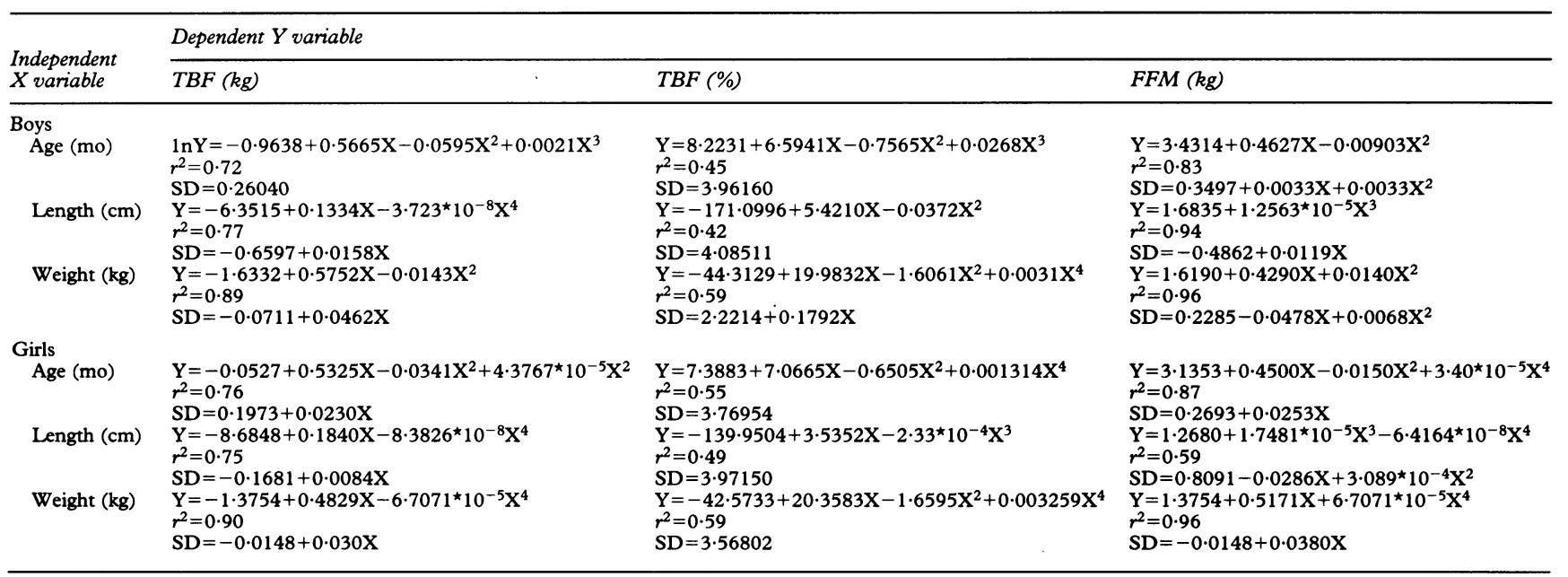

All regressions with non-constant residual SD were obtained by weighted linear stepwise regression, using $1 / \mathrm{SD}^{2}$ as weighting factor. $\mathrm{TBF}=$ total body fat; $\mathrm{FFM}=$ fat-free mass; $\mathrm{SD}=$ residual standard deviation. 


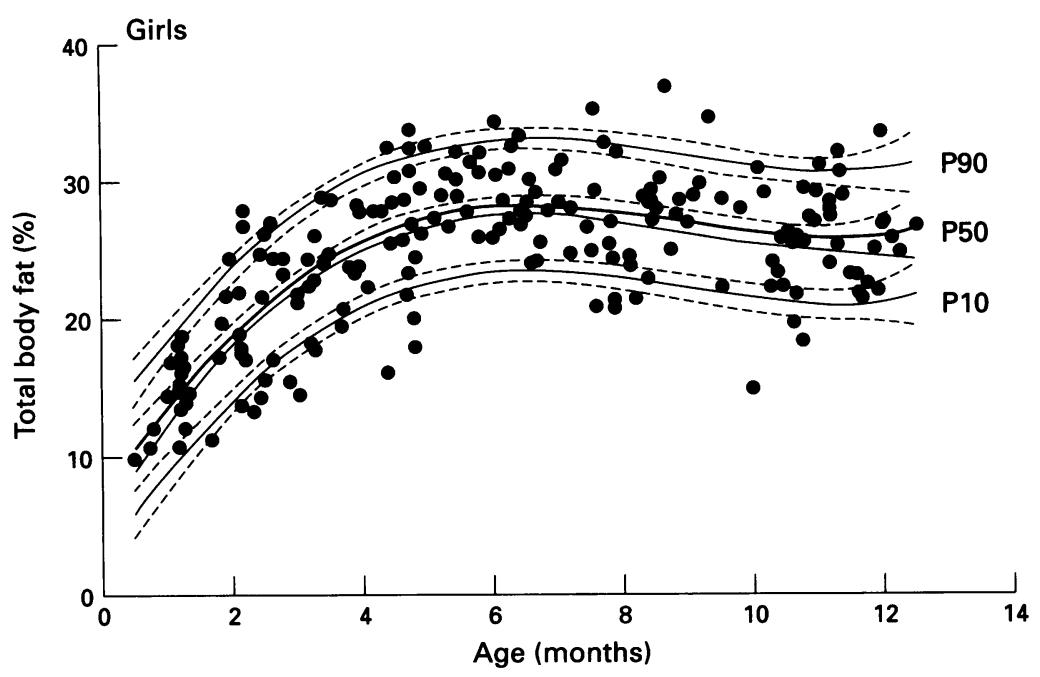

Figure A1 Example of accuracy of centile curves: 10th, 50th, and 90th centiles with accessory $90 \%$ confidence intervals. to be modelled as a function of the $\mathrm{X}$ variable, the appropriate regression equation of the absolute residuals against the $X$ variable, as multiplied by the factor $V(\pi / 2)$, has been supplied in the table. From these regression coefficients the centile charts can easily be reproduced as clarified above and standard deviation scores can be calculated by :

(actual $\mathrm{Y})-(\mathrm{P} 50$ value of $\mathrm{Y}$ for corresponding $\mathrm{X}$ value) (SD for corresponding $\mathrm{X}$ value)

ACCURACY OF THE CENTILE STANDARDS

The accuracy of an estimated centile $\mathrm{P} 50+\mathrm{k} \cdot \mathrm{SD}$ can be judged by computing its $90 \%$ confidence interval as $\mathrm{P} 50+\mathrm{k} \cdot \mathrm{SD} \pm$ $1 \cdot 65 \cdot \mathrm{SE}(\mathrm{P} 50+\mathrm{k} \cdot \mathrm{SD})$. The standard error is determined as $\left.\mathrm{SE}(\mathrm{P} 50+\mathrm{k} \cdot \mathrm{SD})=\sqrt{ } \mathrm{SE}(\mathrm{P} 50)^{2}+\mathrm{k}^{2} \cdot \mathrm{SE}(\mathrm{SD})^{2}\right]$. The standard error of $P 50$ is given by the usual formula for the standard error of the predicted value in multiple regression, see for instance ${ }^{36}$. In case SD does not depend on $\mathrm{X}$, the standard error of SD is given by $S D / V(2 n)^{37}$; otherwise this might be used as an approximate formula. As an illustration, in fig Al the $90 \%$ confidence intervals for the 10th, 50th, and 90th centile are given for TBF (\%) in relation to age in girls.

1 Widdowson EM, McCance RA. The effect of finite periods of undernutrition at different ages on the composition and subsequent development of the rat. Proc $R$ Soc Lond 1963, Ser B 152: 329-42.

2 Lechtig A. Early malnutrition, growth and development. In: Gracey M, Falkner F, eds. Nutritional needs and assessment of normal growth. Nestlé Nutrition Workshop Series, vol 7. New York: Raven Press, 1991.

3 Barker DJP, Winter PD. Weight in infancy and death from ischaemic heart disease. Lancet 1989; ii: 577-80.

4 Osmond C, Barker DJP, Winter PD, Fall CHD, Simmonds SJ. Early growth and death from cardiovascular disease in women BMF 1993; 307: 1519-24.

5 Susser $M$, Stein $Z$. Timing in prenatal nutrition: a reprise of the Dutch famine study. Nutr Rev 1994; 52: 84-94.

6 Agras WS, Kraemer HC, Berkowitz RI, Hammer LD Influence of early feeding style on adiposity at 6 years of age. F Pediatr 1990; 116: 805-9.

7 Rolland-Cachera MF, Deheeger M, Bellisle F, Sempe M, Guilloud-Bataille $\mathbf{M}$, Patois E. Adiposity rebound in children: a simple indicator for predicting obesity. $A m \mathcal{F}$ Clin Nutr 1984; 39: 129-35.

8 Serdula M, Ivery D, Coates R, Freedman D, Williamson D, Byers T. Do obese children become obese adults? review of the literature. Prev Med 1993; 22: 167-77.

9 Dietz WH. Critical periods in childhood for the development of obesity. Am ₹ Clin Nutr 1994; 59: 955-9.

10 Tanner JM, Whitehouse RH. Revised standards for triceps and subscapular skinfolds in British children. Arch Dis Child 1975; 50: 142-5.

11 Oakley JR, Parsons RJ, Whitelaw AGL. Standards for skinfold thickness in British newborn infants. Arch Dis Child 1977; 52: 287-90.

12 Sann L, Durand M, Picard J, Lasne Y, Bethenod M. Arm fat and muscle areas in infancy. Arch Dis Child 1988; 63: 256-60.

13 Frisancho AR. Anthropometric standards for the assessment of growth and nutritional status. Ann Arbor: The University of Michigan Press, 1990.

14 De Bruin NC, Van Velthoven CAM, Stijnen T, Juttmann RE, Degenhart HJ, Visser HKA. Body fat and fat-free mass in infants: new and classic anthropometric parameters and prediction equations compared with totalmeters and prediction equations compared with totalbody electrica

15 Lohman TG. Skinfolds and body density and their relation to body fatness: a review. Hum Biol 1981; 53: 181-225.

16 Davies SW, Lucas A. The prediction of total body fatness in early infancy. Early Hum Dev 1990; 21: 193-8.

17 Trowbridge FL, Graham GG, Wong WW, et al. Body water measurements in premature and older infants using
$\mathrm{H}_{2}{ }^{18} \mathrm{O}$ isotopic determinations. Pediatr Res 1984; 18: 524-7.

18 De Bruin NC, Van Velthoven CAM, Stijnen T, Juttmann RE, Degenhart HJ, Visser HKA. Quantitative assessment of infant body fat by anthropometry and total-body electrical conductivity. Am $\mathcal{F}$ Clin Nutr 1995; 61: 279-86.

19 Fiorotto ML. Measurements of total body electrical conductivity for the estimation of fat and fat-free mass. In Whitehead RG, Prentice A, eds. New techniques in nutritional research. San Diego: Academic Press, 1991 281-301.

20 De Bruin NC, Westerterp KR, Degenhart HJ, Visser HKA. Measurement of fat-free mass in infants. Pediatr Res 1995; 38: 411-7.

21 EM-SCAN Inc. Operator's manual. Springfield, Illinois, 1989.

22 De Bruin NC, Luijendijk IHT, Visser HKA, Degenhart HJ. Effect of alterations in physical and chemical characteristics on TOBEC-derived body composition estimates: validation with non-human models. Phys Med Biol 1994; 39: 1143-56.

23 Fiorotto ML, De Bruin NC, Brans YW, Degenhart HJ, Visser HKA. Total body electrical conductivity measurements: an evaluation of current instrumentation for infants. Pediatr Res 1995: 37: 94-100.

24 Altman DG. Construction of age-related reference centiles using absolute residuals. Stat Med 1993; 12: 917-24.

25 Roede MJ, Van Wieringen JC. Growth diagrams 1980. Netherlands third nation-wide survey. Tijdschrift voor Sociale Gezondheidszorg, 1985; 63 (suppl): 1-34.

26 Draper N, Smith H. Applied regression analysis, 2nd ed. New York: John Wiley and Sons, 1981.

27 Widdowson EM, Dickerson JWT. Chemical composition of the body. In: Comar CL, Bronner F, eds. Mineral meta bolism. An advanced treatise. Volume II. The elements. Par $A$. New York: Academic Press, 1964: 17-35.

28 Fomon SJ. Body composition of the male reference infant during the first year of life. Borden award Address, October 1966. Pediatrics 1967; 40: 863-70.

29 Fomon SJ, Haschke F, Ziegler EE, Nelson SE. Body composition of reference children from birth to age 10 years. Am $\mathcal{F}$ Clin Nutr 1982; 35: 1169-75.

30 Cross JH, Holden C, MacDonald A, Pearmain G, Steven MCG, Booth IW. Clinical examination compared with anthropometry in evaluating nutritional status. Arch Dis anthropometry in evalu

31 Davies PSW, Lucas A. Quetelet's index as a measure of body fatness in young infants. Early Human Dev 1989; 20: 135-41.

32 Dauncey MJ, Gandy G, Gairdner D. Assessment of tota body fat in infancy from skinfold thickness measurements. Arch Dis Child 1977; 52: 223-7.

33 Kabir N, Forsum E. Estimation of total body fat and subcutaneous adipose tissue in full-term infants less than months old. Pediatr Res 1993; 34: 448-54.

34 Cochran WJ, Fiorotto ML, Sheng HP, Klish WJ. Reliability of fat-free mass estimates derived from total-body electrical conductivity measurements as influenced by changes in extracellular fluid volume. Am $\mathcal{f}$ Clin Nutr 1989; 49: in extracel $29-32$.

35 Fiorotto ML, Cochran WJ, Funk RC, Sheng HP, Klish WJ. Total body electrical conductivity measurements: effects of body composition and geometry. Am J Physiol 1987; 252: R794-800.

36 Draper N, Smith H. Applied regression analysis, 2nd ed. New York: John Wiley, 1981 .

37 Kendall M, Stuart A. The advanced theory of statistics, 4th ed. London: Charles Griffin, 1976: 250. 